\title{
Updated Operational Protocols for the U.S. Geological Survey Precipitation Chemistry Quality Assurance Project in Support of the National Atmospheric Deposition Program
}

Open-File Report 2016-1213 



\section{Updated Operational Protocols for the U.S. Geological Survey Precipitation Chemistry Quality Assurance Project in Support of the National Atmospheric Deposition Program}

By Gregory A. Wetherbee and RoseAnn Martin

Open-File Report 2016-1213 


\title{
U.S. Department of the Interior SALLY JEWELL, Secretary
}

\section{U.S. Geological Survey Suzette M. Kimball, Director}

\author{
U.S. Geological Survey, Reston, Virginia: 2017
}

For more information on the USGS - the Federal source for science about the Earth, its natural and living resources, natural hazards, and the environment—visit http://www.usgs.gov or call 1-888-ASK-USGS.

For an overview of USGS information products, including maps, imagery, and publications, visit http://store.usgs.gov/.

Any use of trade, firm, or product names is for descriptive purposes only and does not imply endorsement by the U.S. Government.

Although this information product, for the most part, is in the public domain, it also may contain copyrighted materials as noted in the text. Permission to reproduce copyrighted items must be secured from the copyright owner.

Suggested citation:

Wetherbee, G.A., and Martin, RoseAnn, 2017, Updated operational protocols for the U.S. Geological Survey Precipitation Chemistry Quality Assurance Project in support of the National Atmospheric Deposition Program: U.S. Geological Survey Open-File Report 2016-1213, 18 p., https://doi.org/10.3133/ofr20161213.

ISSN 2331-1258 (online) 


\section{Contents}

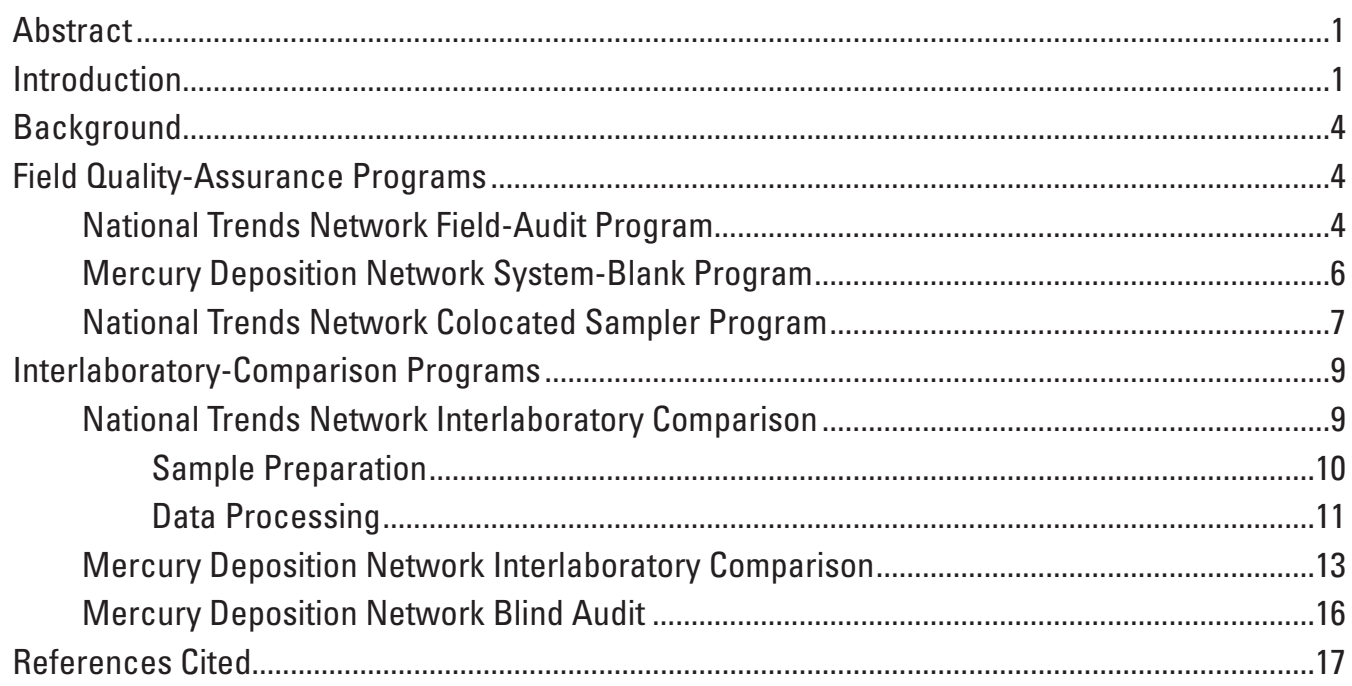

\section{Figures}

1. Locations of National Atmospheric Deposition Program/National Trends Network monitoring sites as of May 1, 2016.

2. Locations of National Atmospheric Deposition Program/Mercury Deposition Network monitoring sites as of May 1, 2016

3. Diagram for the Precipitation Chemistry Quality Assurance Project field-audit and system-blank programs.

4. Diagram for the Precipitation Chemistry Quality Assurance Project interlaboratory-comparison program for the National Trends Network

5. Example of a control chart for Central Analytical Laboratory performance for ammonium ion concentration analyses, 2009-11

6. Example of a $z$-value plot for evaluation of laboratory bias in total mercury concentration analyses

7. Example of an absolute percent difference chart for evaluation of nitrate analysis precision for the Central Analytical Laboratory obtained from the Precipitation Chemistry Quality Assurance Project Web site

8. Diagram for the Precipitation Chemistry Quality Assurance Project interlaboratory-comparison program for the Mercury Deposition Network. 


\section{Tables}

1. Solution names, number of samples shipped to field sites, and number of samples processed for the National Trends Network field-audit program, 2005-15

2. Solution names, number of samples shipped to field sites, and number of samples processed for the Mercury Deposition Network system-blank program, 2007-15..........7

3. Historical summary of the Precipitation Chemistry Quality Assurance Project colocated sampler program, 1988-2016

4. Historical summary of laboratory participation in the Precipitation Chemistry Quality Assurance Project interlaboratory-comparison program for the National Trends Network, 2005-16.

5. Historical summary of laboratory participation in the Precipitation Chemistry Quality Assurance Project interlaboratory-comparison program for the Mercury Deposition Network, 2007-16

\section{Conversion Factors}

\begin{tabular}{|c|c|c|}
\hline Multiply & By & To obtain \\
\hline \multicolumn{3}{|c|}{ Length } \\
\hline centimeter (cm) & 0.3937 & inch (in.) \\
\hline millimeter $(\mathrm{mm})$ & 0.03937 & inch (in.) \\
\hline meter (m) & 3.281 & foot $(\mathrm{ft})$ \\
\hline kilometer (km) & 0.6214 & mile (mi) \\
\hline kilometer (km) & 0.5400 & mile, nautical (nmi) \\
\hline meter $(\mathrm{m})$ & 1.094 & yard (yd) \\
\hline inch (in.) & 2.54 & centimeter $(\mathrm{cm})$ \\
\hline \multicolumn{3}{|c|}{ Area } \\
\hline square meter $\left(\mathrm{m}^{2}\right)$ & 0.0002471 & acre \\
\hline hectare (ha) & 2.471 & acre \\
\hline square kilometer $\left(\mathrm{km}^{2}\right)$ & 247.1 & acre \\
\hline square meter $\left(\mathrm{m}^{2}\right)$ & 10.76 & square foot $\left(\mathrm{ft}^{2}\right)$ \\
\hline square centimeter $\left(\mathrm{cm}^{2}\right)$ & 0.1550 & square inch $\left(\mathrm{ft}^{2}\right)$ \\
\hline hectare (ha) & 0.003861 & square mile $\left(\mathrm{mi}^{2}\right)$ \\
\hline \multicolumn{3}{|c|}{ Volume } \\
\hline liter (L) & 33.82 & ounce, fluid (fl. oz) \\
\hline \multicolumn{3}{|c|}{ Density } \\
\hline gram per cubic centimeter $\left(\mathrm{g} / \mathrm{cm}^{3}\right)$ & 62.4220 & pound per cubic foot $\left(\mathrm{lb} / \mathrm{ft}^{3}\right)$ \\
\hline
\end{tabular}

Temperature in degrees Celsius $\left({ }^{\circ} \mathrm{C}\right)$ may be converted to degrees Fahrenheit $\left({ }^{\circ} \mathrm{F}\right)$ as follows:

${ }^{\circ} \mathrm{F}=\left(1.8 \mathrm{x}^{\circ} \mathrm{C}\right)+32$

Temperature in degrees Fahrenheit $\left({ }^{\circ} \mathrm{F}\right)$ may be converted to degrees Celsius $\left({ }^{\circ} \mathrm{C}\right)$ as follows:

${ }^{\circ} \mathrm{C}=\left({ }^{\circ} \mathrm{F}-32\right) / 1.8$ 


\section{Datum}

Horizontal coordinate information is referenced to the North American Vertical Datum of 1983 (NAVD 83).

\section{Supplemental Information}

Specific conductance is given in microsiemens per centimeter at 25 degrees Celsius $\left(\mu \mathrm{S} / \mathrm{cm}\right.$ at $\left.25^{\circ} \mathrm{C}\right)$.

Concentrations of chemical constituents in water are given either in milligrams per liter $(\mathrm{mg} / \mathrm{L})$, micrograms per liter $(\mu \mathrm{g} / \mathrm{L})$, or nanograms per liter $(\mathrm{ng} / \mathrm{L})$.

A water year is the 12-month period October 1 through September 30 designated by the calendar year in which it ends.

\section{Abbreviations}

absolute value of $x=|x|$, where $x$ takes the form of numerical values or algebraic expressions

$\mu \mathrm{g} / \mathrm{L} \quad$ micrograms per liter

$\mu \mathrm{S} / \mathrm{cm} \quad$ microsiemens per centimeter at 25 degrees Celsius

$\mathrm{mg} / \mathrm{L} \quad$ milligrams per liter

$\mathrm{ng} / \mathrm{L} \quad$ nanograms per liter

ACM AeroChem Metrics

APD Absolute percent difference

BOS Branch of Quality Systems

CAL Central Analytical Laboratory, Illinois State Water Survey

DI Deionized water

ETI Noah-IV Environmental Technologies, Inc. Noah-IV rain gage

$f$-psig $\quad f$-pseudosigma

GMOS Global Mercury Observation System

HAL Mercury Analytical Laboratory, Eurofins Frontier Global Sciences, Inc.

$\mathrm{HCl} \quad$ hydrochloric acid

$\mathrm{Hg} \quad$ mercury

HPS High Purity Standards, Inc.

ID identification

MDN Mercury Deposition Network

MPV Most Probable Value 


\section{Abbreviations-Continued}

$\begin{array}{ll}\text { NADP } & \text { National Atmospheric Deposition Program } \\ \text { N-CON } & \text { N-CON Systems, Incorporated } \\ \text { NTN } & \text { National Trends Network } \\ \text { NMCL } & \text { Network Maximum Contamination Level } \\ \text { OTT Pluvio }{ }^{2},-N & \text { OTT Pluvio precipitation gage, Pluvio }{ }^{2} \text { or Pluvio-N (NADP) models } \\ \text { PCQA } & \text { U.S. Geological Survey Precipitation Chemistry Quality Assurance Project } \\ \text { OA } & \text { Quality Assurance } \\ \text { OC } & \text { Quality Control } \\ \text { UCL } & \text { Upper Confidence Limit } \\ \text { USGS } & \text { U.S. Geological Survey }\end{array}$




\title{
Updated Operational Protocols for the U.S. Geological Survey Precipitation Chemistry Quality Assurance Project in Support of the National Atmospheric Deposition Program
}

\author{
By Gregory A. Wetherbee and RoseAnn Martin
}

\begin{abstract}
The U.S. Geological Survey Branch of Quality Systems operates the Precipitation Chemistry Quality Assurance Project (PCQA) for the National Atmospheric Deposition Program/National Trends Network (NADP/NTN) and National Atmospheric Deposition Program/Mercury Deposition Network (NADP/MDN). Since 1978, various programs have been implemented by the PCQA to estimate data variability and bias contributed by changing protocols, equipment, and sample submission schemes within NADP networks. These programs independently measure the field and laboratory components which contribute to the overall variability of NADP wet-deposition chemistry and precipitation depth measurements. The PCQA evaluates the quality of analyte-specific chemical analyses from the two, currently (2016) contracted NADP laboratories, Central Analytical Laboratory and Mercury Analytical Laboratory, by comparing laboratory performance among participating national and international laboratories. Sample contamination and stability are evaluated for NTN and MDN by using externally field-processed blank samples provided by the Branch of Quality Systems. A colocated sampler program evaluates the overall variability of NTN measurements and bias between dissimilar precipitation gages and sample collectors.

This report documents historical PCQA operations and general procedures for each of the external quality-assurance programs from 2007 to 2016.
\end{abstract}

\section{Introduction}

The National Atmospheric Deposition Program/National Trends Network (NADP/NTN) was initiated in 1978 by the Association of State Agricultural Experiment Stations to monitor long-term atmospheric chemistry and the measured effects of environmental pollutants on aquatic and terrestrial systems (National Atmospheric Deposition Program, 1985; Nilles, 2000). As of September 2015, precipitation samples were being collected at 265 NTN sites and 114 MDN sites in the United States, Puerto Rico, U.S.Virgin Islands, Argentina, and Canada. Since 1996, The NADP/Mercury Deposition Network (MDN) has monitored total mercury (Hg) concentrations in precipitation in the United States, Puerto Rico, and Canada. Historically, samples from Mexico were also collected and analyzed. The actual numbers of active sites in the networks change frequently. Figures 1 and 2 show the locations of active sites in the NTN and MDN, respectively, as of May 2016. The U.S. Geological Survey (USGS) Branch of Quality Systems (BQS) began quality-assurance monitoring for NADP/NTN in 1978 and for NADP/MDN in 2004. The quality-assurance programs assess and document the quality of wet-deposition data for NADP/NTN and NADP/MDN.

The Illinois State Water Survey's Central Analytical Laboratory (CAL) located in Champaign, Illinois, has been the contract laboratory for NADP/NTN since 1978. Frontier Geosciences, now Eurofins/Frontier Global Sciences, Inc., located in Bothell, Washington, has been the contract laboratory for NADP/MDN since 1994.

The Precipitation Chemistry Quality Assurance Project (PCQA) has implemented many changes since the project's published protocols were described by Latysh and Wetherbee $(2005,2007)$. This report describes changes to the PCQA programs that occurred between 2007 and 2016. Also, this report provides documentation of projected PCQA operations. This report alone is not a comprehensive account of historical PCQA protocols but is intended to update the previous USGS reports, most importantly See and others (1990) and Latysh and Wetherbee $(2005,2007)$. 


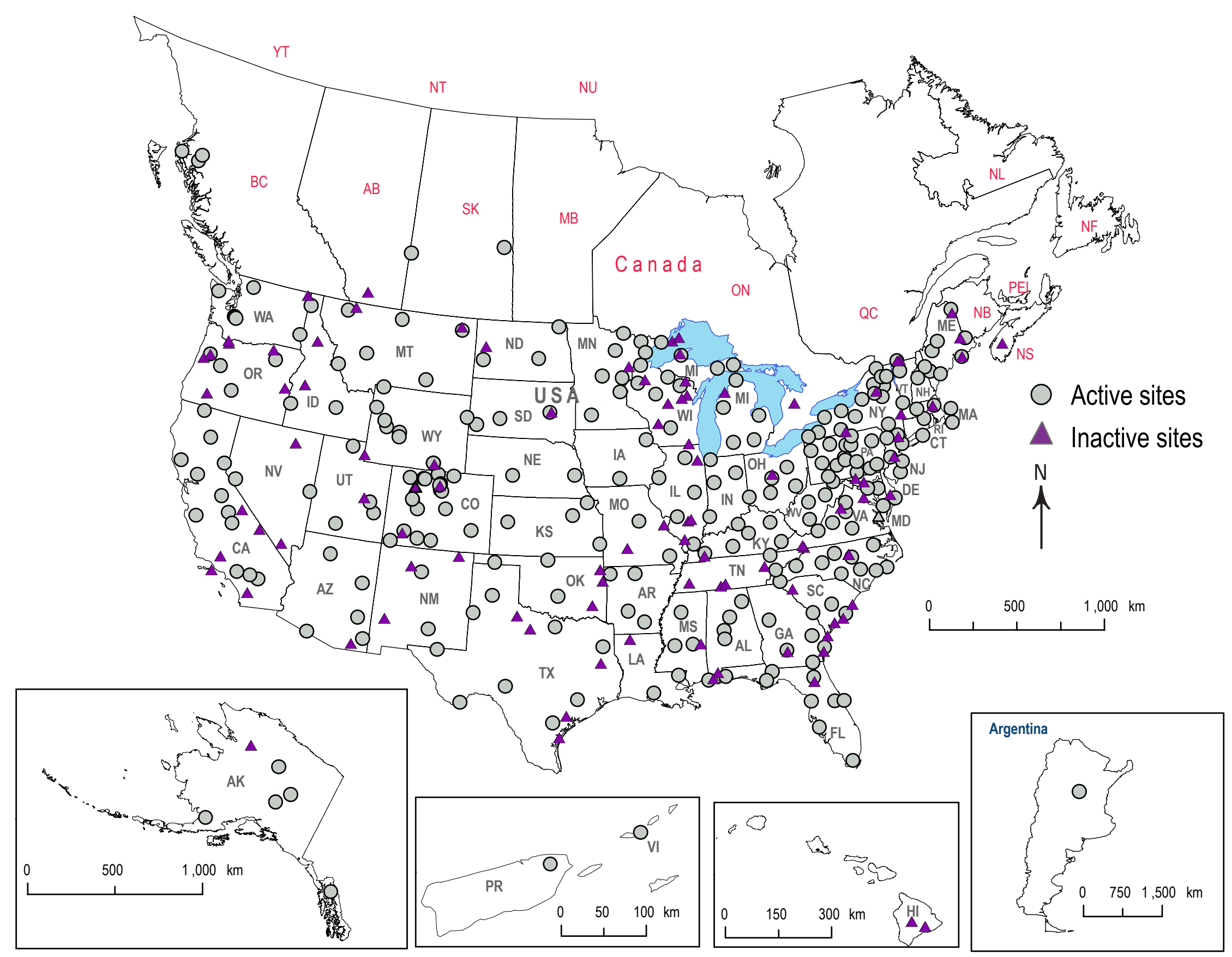

Figure 1. Locations of National Atmospheric Deposition Program/National Trends Network monitoring sites as of May 1, 2016. 


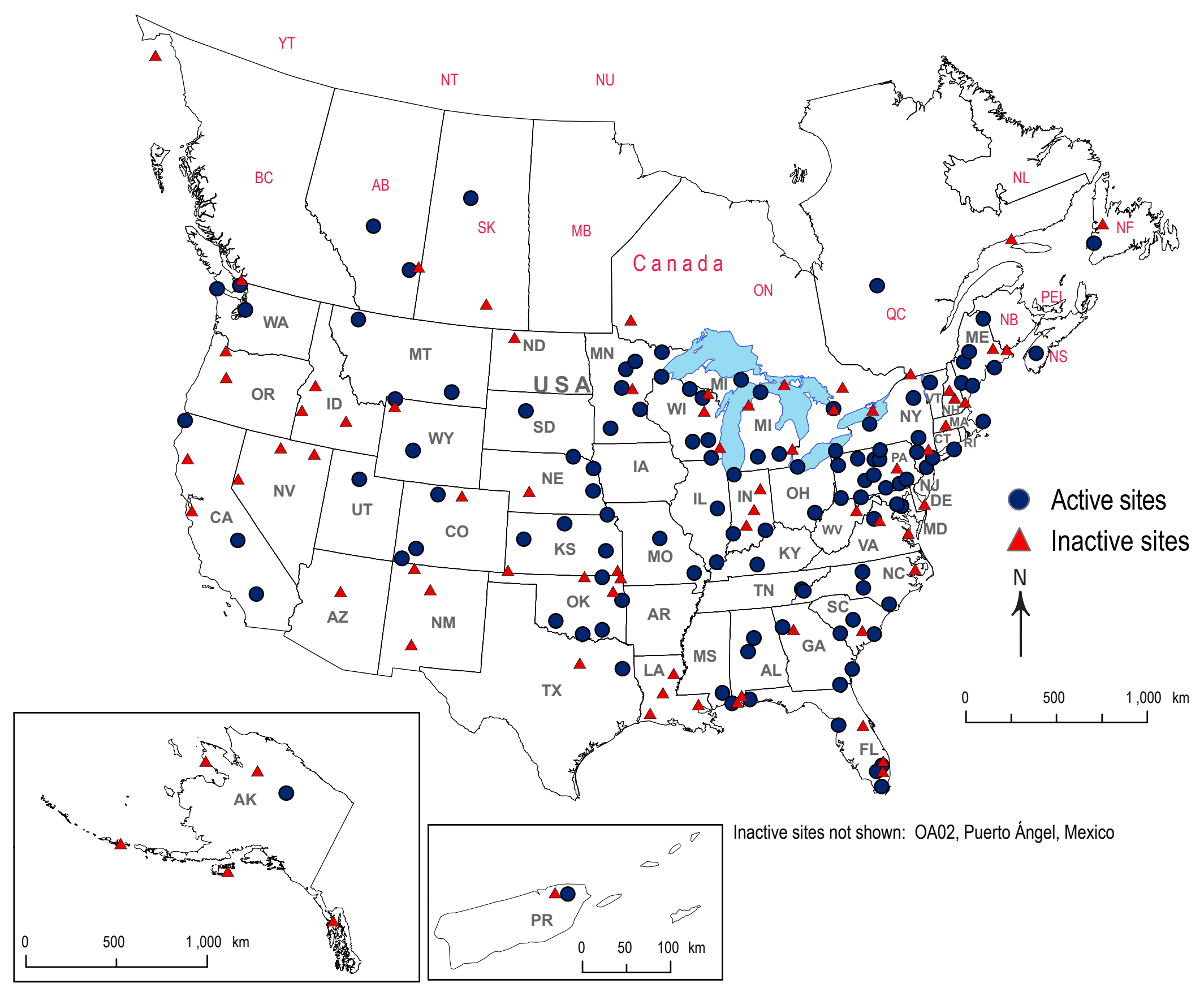


Updated Operational Protocols for the USGS Precipitation Chemistry Quality Assurance Project in Support of NADP

\section{Background}

From 1997 through 2004, USGS operated six external quality-assurance programs for NADP/NTN: (1) intersite comparison, (2) blind audit, (3) interlaboratory comparison, (4) sample-handling evaluation, (5) field audit (formerly field blank), and (6) colocated sampler. In January 2003, the blind-audit program was replaced by the sample-handling evaluation program. Both the blind-audit and sample-handling evaluation programs assessed the effects of sampling equipment, sample handling, shipping, and processing on sample chemistry. These two programs were intended to monitor processes that may introduce contamination to precipitation samples. The intersite-comparison program was designed to assess the accuracy and reliability of field $\mathrm{pH}$ and specific-conductance measurements performed by site operators (Latysh and Gordon, 2004). The intersite-comparison and the sample-handling evaluation programs were discontinued in 2004. The field-audit program started in 1997. Similar to the sample-handling evaluation program, the field-audit program assessed the effects of sample handling, shipping, and processing but has also considered the effects of field exposure on sample chemistry.

Since 1982, the interlaboratory-comparison program for the NTN has evaluated the performance of CAL and provided a comparison of laboratories around the world that analyze low-concentration water samples. Participating laboratories are associated with the major wet-deposition monitoring networks in the Northern Hemisphere, including research laboratories that measure low-ionic-strength water samples. Laboratory participants have changed over the life of the program because of a variety of factors. Some have participated for over 15 years.

The objective of the colocated-sampler program as operated from 1988 to 2007 was to provide a measure of NADP/NTN's overall variability by comparing data collected from two sets of identical precipitation-monitoring instruments situated at an NADP/NTN site. The program's objectives changed in 2008 to answer questions about the new instrumentation added to the NADP networks and to aid in assessment of long-term records that include data from both original and upgraded instrumentation. From 2008 to 2015, the program provided a measure of observed bias between digital precipitation gages (e-gages) and new precipitation collectors. In water year 2016, the program changed again to evaluate overall variability in NADP/NTN chemical measurements by using new identical N-CON Systems, Incorporated (N-CON), collectors. (A water year is the 12-month period October 1 through September 30 designated by the calendar year in which it ends.)

Since 2004, the USGS system-blank program has assessed the effects of sample handling, shipping, and processing, along with the effects of field exposure on MDN sample chemistry. Logistical challenges and lessons learned in the early years of the PCQA programs for MDN resulted in several protocol changes for the system-blank program (Latysh and Wetherbee, 2007). Originally, synthetic precipitation samples made from dilution of stock reference solutions were spiked with $\mathrm{Hg}$ to simulate a natural precipitation matrix. Later it was learned that this $\mathrm{Hg}$-spiked matrix resulted in confounding variability in system-blank data; therefore, all system-blank testing solutions with the potential to contain Hg were eliminated from the program. Systemblank samples now consist solely of deionized water (DI). The Hg content of the USGS DI used for system blanks is tested by the Mercury Analytical Laboratory (HAL) for each quarterly system-blank mailing.

The HAL is located at Eurofins/Frontier Global Sciences, Inc., in Bothell, Wash. Formerly known as Frontier Geosciences, Inc., the laboratory was renamed as Frontier Global Sciences, Inc., in 2009. It was acquired by Eurofins in December 2012. The laboratory relocated from Seattle, Wash., to Bothell, Wash., in December 2011. The USGS interlaboratory-comparison program for MDN has evaluated the performance of the HAL in comparison to international laboratories that also analyze wet-deposition samples and (or) low-ionic-strength waters for total $\mathrm{Hg}$ from 2004 to present.

From 2006 to 2011, the blind-audit program assessed the variability and bias of analytical results produced by the HAL by using double-blind samples. Samples spiked with known amounts of $\mathrm{Hg}$ were disguised as weekly precipitation samples from MDN sites and submitted to the HAL. The blind-audit program was discontinued in 2011 because the benefits of a double-blind program no longer outweighed costly logistical challenges for its implementation.

\section{Field Quality-Assurance Programs}

\section{National Trends Network Field-Audit Program}

The field-audit program (known as the field-blank program prior to 2003) was designed to evaluate the effects of field exposure, sample handling, and processing on precipitation chemistry. The field-audit program was initiated in August 1996 as a pilot study. The program began full operation in July 1997, replacing the weekly analysis of dry-side buckets. The NTN fieldaudit program and MDN system-blank program are described in figure 3.

The procedures for sample preparation by USGS and sample processing by NTN field-site operators are documented by Latysh and Wetherbee (2005). Throughout 2005-9, nearly every NTN site received a field-audit sample each year. Starting in 2010, field-audit samples were shipped to 50 sites every 6 months (that is, 100 sites annually). Individual sites participate at most once per year. A history of the field-audit solutions used in 2005-15 is shown in table 1 . The chemical composition of 


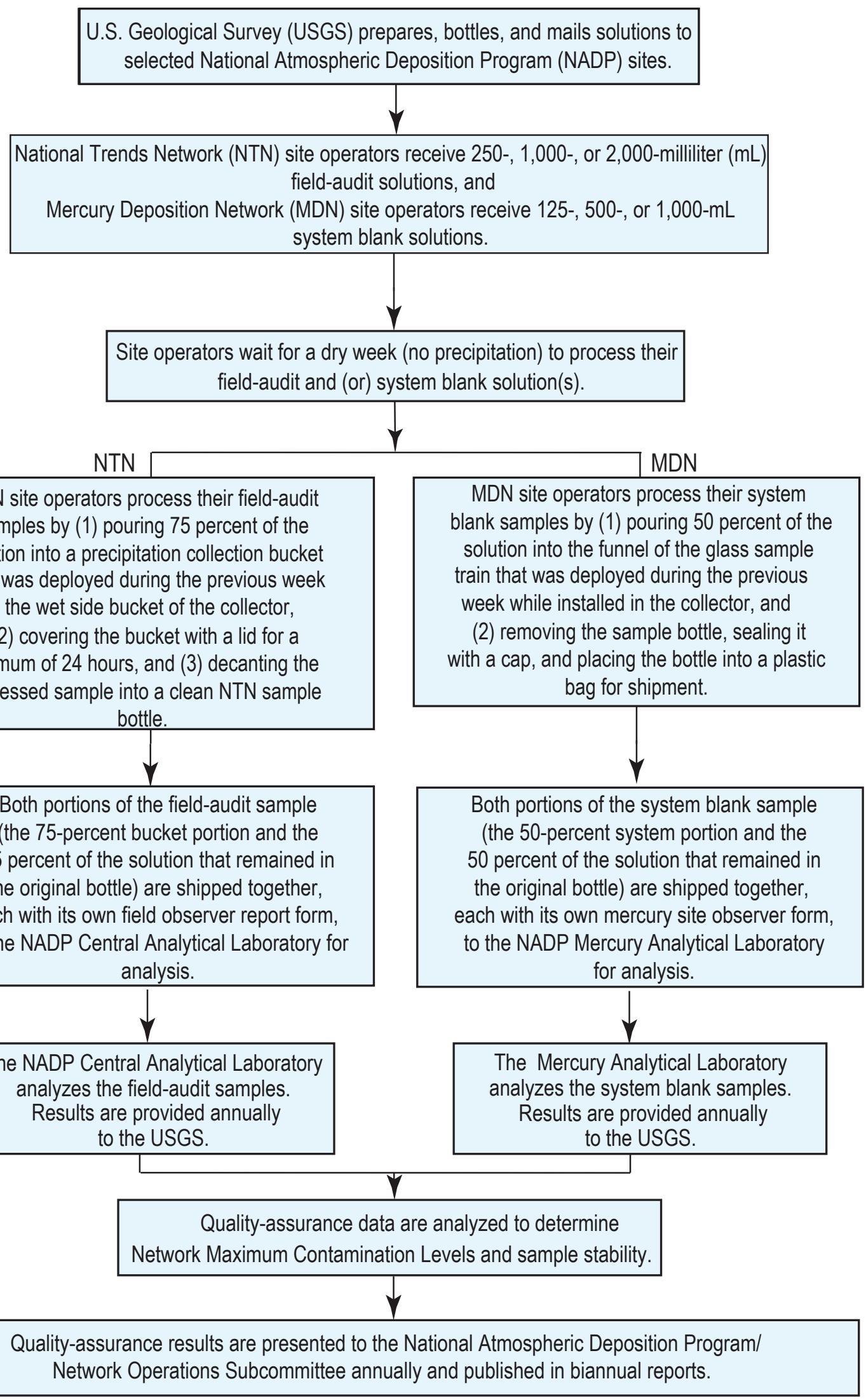

Figure 3. Diagram for the Precipitation Chemistry Quality Assurance Project field-audit and system-blank programs. 
field-audit solutions has changed periodically to reflect the range of concentrations measured in NTN samples. Bromide ion was added to the composition of some of the field-audit solutions in 2011. The most probable values for the chemical concentrations in each field-audit solution are published in USGS reports that document the external quality assurance results for the PCQA (Wetherbee and others, 2006, 2009, 2010, 2013; Wetherbee and Martin, 2014).

Analysis and interpretation of field-audit data were revised in 2004 with the introduction of the Network Maximum Contamination Level (NMCL) concept (Wetherbee and others, 2009). The NMCLs for each chemical constituent are calculated annually as the 90-percent upper confidence limit (UCL) on the 90th percentile of the bucket-minus-bottle field-audit paired concentration differences. Statistical UCLs for contamination percentiles provide an estimate of the amount of contamination that is not likely to be exceeded in a large percentage of NTN samples. The statistical basis for the calculations are described by Hahn and Meeker (1991). The NMCLs serve as practical limits of quantitation for the network (Wetherbee and others, 2010, 2013).

Table 1. Solution names, number of samples shipped to field sites, and number of samples processed for the National Trends Network field-audit program, 2005-15.

[DI, ultrapure deionized water; SP, synthetic precipitation solution]

\begin{tabular}{clcc}
\hline $\begin{array}{c}\text { Calendar } \\
\text { year }\end{array}$ & \multicolumn{1}{c}{$\begin{array}{c}\text { Solution } \\
\text { names }\end{array}$} & $\begin{array}{c}\text { Number of samples } \\
\text { shipped to sites }\end{array}$ & $\begin{array}{c}\text { Number of samples } \\
\text { processed }\end{array}$ \\
\hline 2005 & DI, SP-2, SP-3, SP-5, SP-98 & 256 & 164 \\
2006 & DI, SP-2, SP-3, SP-17 & 255 & 164 \\
2007 & DI, SP-2, SP-3, SP-17 & 254 & 181 \\
2008 & DI, SP-2, SP-3, SP-17 & 241 & 141 \\
2009 & DI, SP-2, SP-3, SP-17 & 100 & 67 \\
2010 & DI, SP-2, SP-3, SP-17 & 99 & 68 \\
2011 & DI, SP-2, SP-3, SP-17 & 100 & 74 \\
2012 & DI, SP-2, SP-3, SP-17 & 100 & 61 \\
2013 & DI, SP-2, SP-3, SP-17 & 100 & 54 \\
2014 & DI, SP-2, SP-3, SP-17 & 100 & 43 \\
2015 & DI, SP-2, SP-3, SP-17 & 100 & 49 \\
\hline
\end{tabular}

\section{Mercury Deposition Network System-Blank Program}

The system-blank program was designed to mimic the field-audit program and assess potential effects to Hg sample concentrations resulting from sample collection, processing, and analysis. A general description of the program is provided by Latysh and Wetherbee (2007). Minor changes to the protocols are described herein. An updated diagram of the system-blank program is shown in figure 3.

Between 2007 and 2015, different volumes and Hg concentrations were used for system-blank solutions (Wetherbee and others, 2006, 2009, 2010, 2013; Wetherbee and Martin, 2014). The Hg-spiked synthetic rainwater solutions were used for the system blanks from March 2004 to March 2006 (Wetherbee and others, 2006, 2009, 2010, 2013; Wetherbee and Martin, 2014). In June 2006, it was determined that these solutions were not stable and thus spiking with $\mathrm{Hg}$ ceased. Testing of the synthetic precipitation stock solutions in March 2007 revealed trace quantities of $\mathrm{Hg}$, which complicated interpretation of system-blank results. Beginning in June 2007, all system blanks have utilized Hg-free, ultrapure DI with no preservation (Wetherbee and others, 2006, 2009, 2010, 2013; Wetherbee and Martin, 2014).

From 2004 to March 2007, system-blank samples were shipped to the field sites in acid-cleaned reused Teflon bottles. This practice was also discontinued because of variable low-level $\mathrm{Hg}$ contamination in the Teflon bottles. Single-use borosilicate glass bottles that are certified free of trace-element contamination have been used for the program since June 2007. Unlike Teflon bottles, the glass bottles are susceptible to breaking and occasional leakage during shipment, but the quality of the chemical data for system-blank samples has improved. A history of the changes in the system-blank program is summarized in table 2.

Analysis and interpretation of system-blank data were revised in 2004 with the introduction of the concept of the NMCL (Wetherbee and others, 2009). The NMCL for Hg has been calculated annually as the 90-percent UCL on the 90th percentile of the system-minus-bottle Hg-concentration differences. The NMCL for Hg in MDN samples has been interpreted as the maximum $\mathrm{Hg}$ contamination in 90 percent of the MDN samples with 90 percent confidence and serves as a practical limit of quantitation for the network (Wetherbee and others, 2010, 2013). 


\section{National Trends Network Colocated Sampler Program}

From 1988 through 2007, the colocated-sampler program evaluated the overall variability (error) associated with collecting, handling, processing, and analyzing NADP/NTN wet-deposition samples. Overall variability was estimated by comparing data collected by duplicate sets of equipment installed at NADP/NTN sites primarily on a water-year basis (October 1 through September 30), with the exception of 1994 when colocated sites were operated on a calendar-year basis (Gordon and others, 2003; Wetherbee and others, 2005). In 1997, the number of sites colocated each water year was reduced from four sites to two to reduce cost. Sites NH02, at Hubbard Brook in New Hampshire (2000-1), and WI98, at Wildcat Mountain State Park in Wiscon$\sin (2002-3)$, each hosted colocated sampling equipment for 2 consecutive years.

The NADP/NTN began to transition to a digital precipitation-monitoring platform in 2005 with the approval of the ETI Noah-IV and OTT Pluvio-N e-gages. In 2009, the OTT Pluvio ${ }^{2}$ e-gage was accepted as a substitute for the OTT Pluvio-N e-gage. These changes are documented in NADP Joint Subcommittee meetings minutes for

- 2005 (http://nadp.sws.uiuc.edu/committees/minutes/spr05/joint2005spr.pdf), and

- 2010 (http://nadp.sws.uiuc.edu/committees/minutes/spring2009/nos-dmas2009spr.pdf).

The N-CON bucket-type collector was approved for NTN use in 2010 (http://nadp.sws.uiuc.edu/committees/minutes/fall2010/ nos2010fall.pdf, accessed May 9, 2016).

The colocated sampler program transitioned to investigate the potential shifts in precipitation depth and chemistry measurements resulting from these changes in NADP-approved instrumentation in 2005. From 2005 to 2009, sites AZ03 at Grand Canyon National Park; VT99 at Underhill, Vermont; and WI98 hosted long-term colocated studies to evaluate NADP/NTN's transition to updated, modern field instruments. In 2009, the colocated program transitioned back to operating single water-year studies. Identical ETI Noah-IV, OTT Pluvio-N, or OTT Pluvio ${ }^{2}$ precipitation gages were colocated to evaluate e-gage variability. The old AeroChem Metrics Model 301 (ACM) collectors were colocated with N-CON collectors to evaluate collector bias. The program obtained 12 years of colocated data by using this configuration.

Beginning in water year 2016, the colocated program objectives transitioned again. Identical N-CON NTN collectors are now colocated to evaluate overall variability in sample chemistry. Precipitation gages are no longer colocated. A history of the colocated program is summarized in table 3 .

Table 2. Solution names, number of samples shipped to field sites, and number of samples processed for the Mercury Deposition Network system-blank program, 2007-15.

[DI, ultrapure deionized water; HAL, Mercury Analytical Laboratory for the Mercury Deposition Network; Hg, mercury; USGS, U.S. Geological Survey; BQS, U.S. Geological Survey Branch of Quality Systems; SP, synthetic precipitation]

\begin{tabular}{cllcc}
\hline $\begin{array}{c}\text { Calendar } \\
\text { year }\end{array}$ & \multicolumn{1}{c}{$\begin{array}{c}\text { Solution } \\
\text { names }\end{array}$} & \multicolumn{1}{c}{$\begin{array}{c}\text { Solution } \\
\text { description }\end{array}$} & $\begin{array}{c}\text { Number of samples } \\
\text { shipped to sites }\end{array}$ & $\begin{array}{c}\text { Number of samples } \\
\text { processed }^{1}\end{array}$ \\
\hline 22007 & DI & DI made/bottled at BQS & 66 & 44 \\
& SP2 unspiked & SP2, no Hg spike & 18 & 13 \\
& SP3 unspiked & SP3, no Hg spike & 18 & 13 \\
2008 & DI-HAL & DI made/bottled at HAL & 53 & 40 \\
& DI-USGS & DI made/bottled at BQS & 51 & 31 \\
2009 & DI-HAL & DI made/bottled at HAL & 35 & 23 \\
& DI-USGS & DI made/bottled at BQS & 48 & 30 \\
2010 & DI-USGS & DI made/bottled at BQS & 115 & 69 \\
2011 & DI-USGS & DI made/bottled at BQS & 106 & 74 \\
2012 & DI-USGS & DI made/bottled at BQS & 99 & 67 \\
2013 & DI-USGS & DI made/bottled at BQS & 97 & 66 \\
2014 & DI-USGS & DI made/bottled at BQS & 92 & 52 \\
2015 & DI-USGS & DI made/bottled at BQS & 104 & 54 \\
\hline
\end{tabular}

${ }^{1}$ Sites at least attempted to participate but all did not submit samples for chemical analysis. Some sites process samples received in the previous year.

${ }^{2}$ Transitioned from Teflon bottles to glass bottles during 2007. 
Table 3. Historical summary of the Precipitation Chemistry Quality Assurance Project colocated sampler program, $1988-2016$.

[NTN site IDs, National Trends Network site identifiers; OTT, OTT division of HACH Company; ETI, Environmental Technologies, Inc.; ACM, Aerochem Metrics model 301 wet/dry precipitation collector; N-CON NTN, N-CON Systems, Inc., bucket-type precipitation collector for National Trends Network; YES, Yankee Environmental Systems, Inc., prototype precipitation collector; NPS, National Park Service]

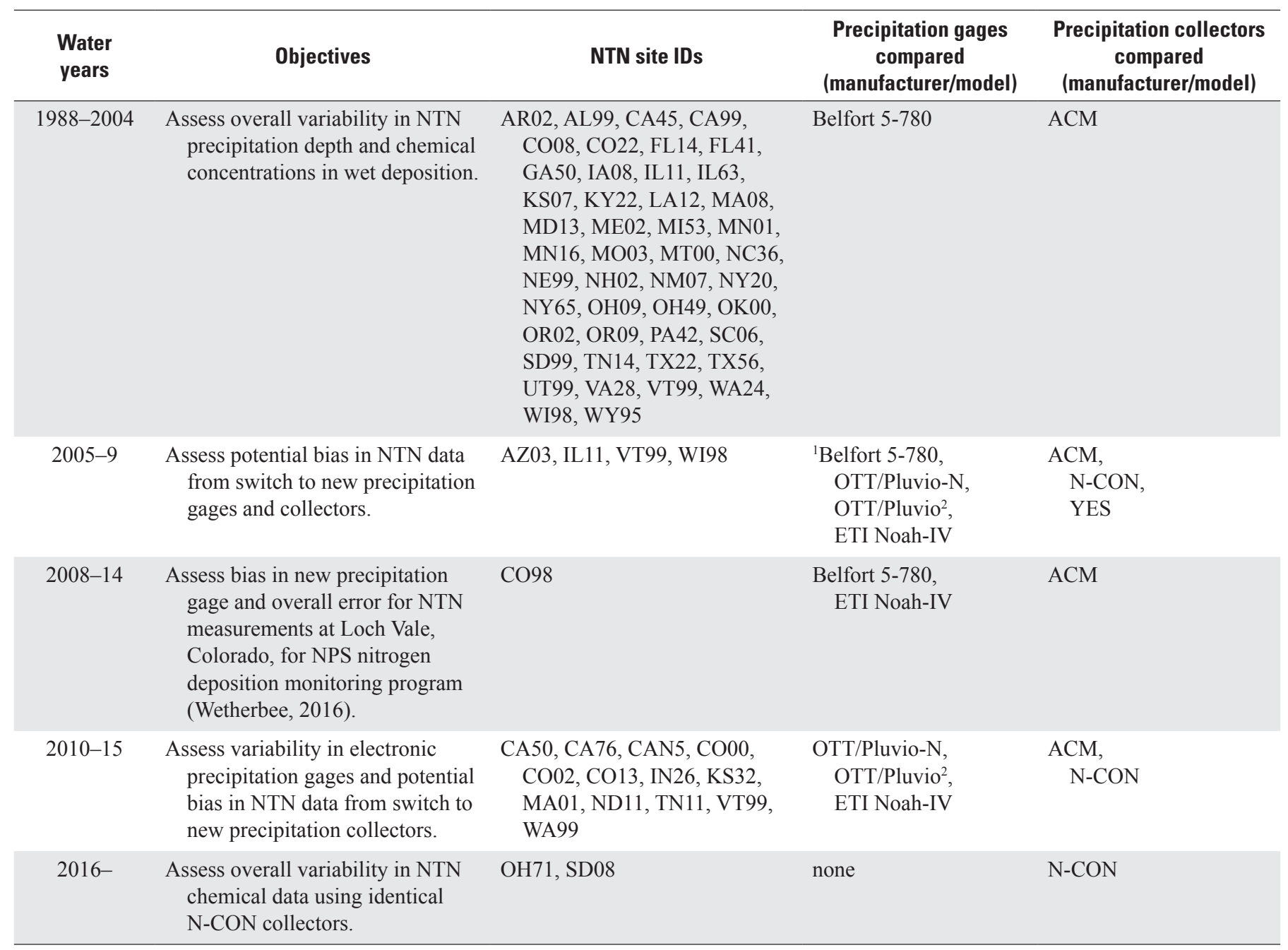

${ }^{1}$ Switched out Belfort 5-780 with ETI/Noah-IV in August 2007.

The protocols for the colocated sampler program for the period 2009-15 were similar to those described in Latysh and Wetherbee (2005). Exceptions include elimination of testing the operating temperatures and electrical resistances of the collectors' precipitation sensors and performing calibration tests of the precipitation gages because data from these tests served no useful purpose. Colocation of ACM and $\mathrm{N}-\mathrm{CON}$ collectors required that

1. the ACM and N-CON collectors open immediately in response to application of simulated precipitation,

2. the collectors close upon drying of the sensor or cessation of simulated precipitation, and

3. the precipitation gage records lid opening events. 


\section{Interlaboratory-Comparison Programs}

\section{National Trends Network Interlaboratory Comparison}

The interlaboratory-comparison program for the NTN has been designed to (1) evaluate the analytical precision and accuracy of data produced by participating laboratories, (2) quantify the uncertainty of chemical analyses for concentrations reported by CAL, and (3) compare the CAL's performance to that of international laboratories that analyze low-ionic-strength water samples. The program was initiated in 1982 with three participating laboratories. During subsequent years, many laboratories have joined and dropped out of the program. From 1982 to 2007, four synthetic and natural precipitation samples were shipped to the laboratories every 2 weeks. The number of samples was reduced to four samples per month in 2007 because of requests for reduced sample loads from several participating laboratories. A diagram of the NTN interlaboratory-comparison program is provided in figure 4 . A history of laboratory participation in the program is provided in table 4 .

Natural rainwater samples

Illinois State Water Survey, Central Analytical Laboratory, prepares natural wet-deposition samples collected from National Atmospheric Deposition Program/National Trends Network (NADP/NTN) sites and ships them to the U.S. Geological Survey (USGS).

Laboratory-prepared synthetic rainwater samples Vendor prepares stock solutions from National Institute of Standards and Technology-certified traceable reference materials and delivers them to the USGS.

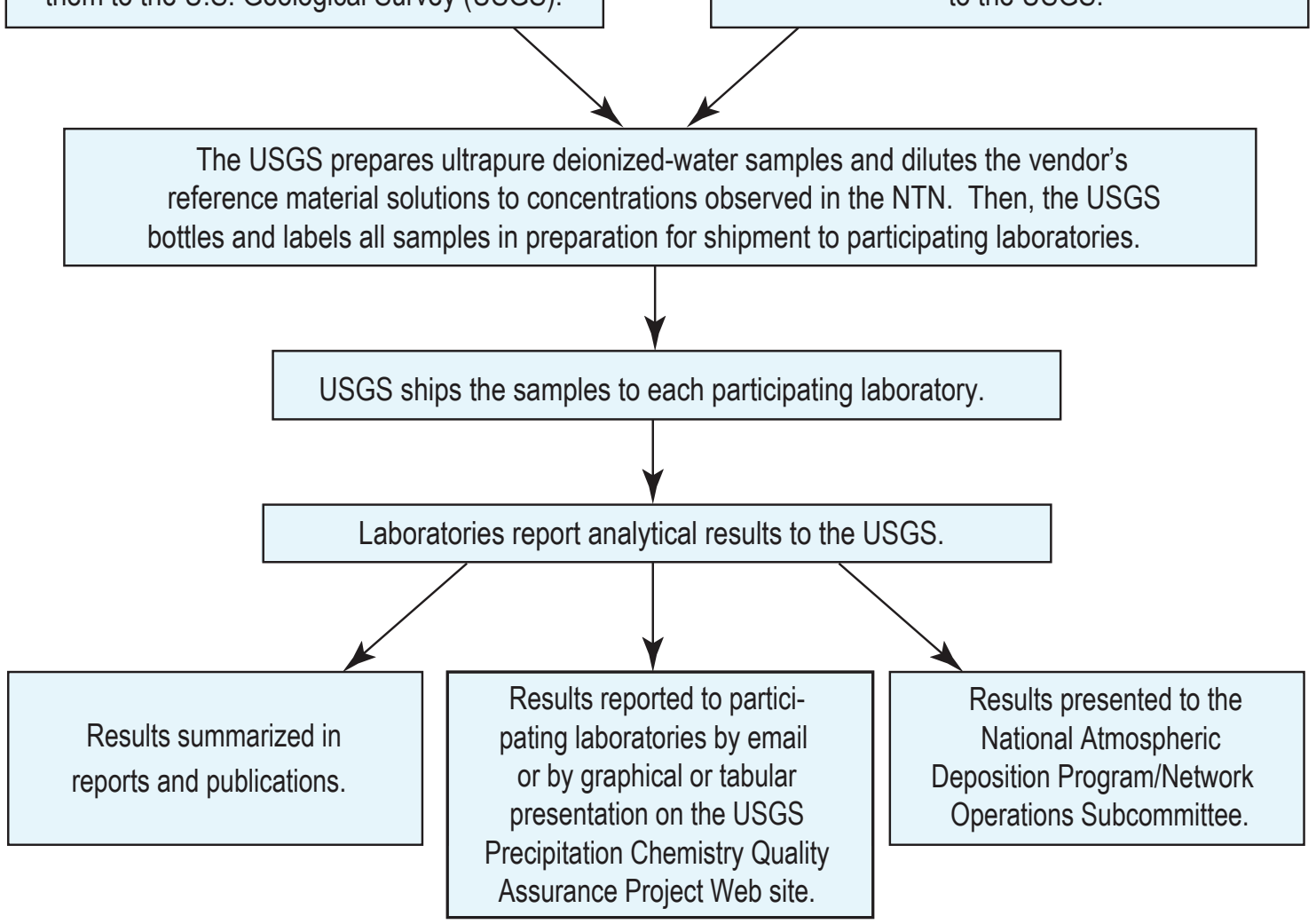

Figure 4. Diagram for the Precipitation Chemistry Quality Assurance Project interlaboratory-comparison program for the National Trends Network. 
Table 4. Historical summary of laboratory participation in the Precipitation Chemistry Quality Assurance Project interlaboratorycomparison program for the National Trends Network, 2005-16.

[ADORC, Acid Deposition and Oxidant Research Center, Niigata-shi, Japan; CAL, National Atmospheric Deposition Program Central Analytical Laboratory, Illinois State Water Survey, Champaign, Illinois; MACTEC, MACTEC, Inc., Gainesville, Florida; MOEE, Ontario Ministry of the Environment and Energy, Dorset, Ontario, Canada; MSC, Meteorological Services of Canada; NILU, Norwegian Institute for Air Research, Kjeller, Norway; NYSDEC, New York State Department of Environmental Conservation Bureau of Air Quality Surveillance, Albany, New York; SA, Shepard Analytical Service, Simi Valley, California; ECST, Environment Canada Science and Technology Branch, Downsview, Ontario, Canada (formerly MSC); ACAP, Asia Center for Air Pollution Research (formerly ADORC); CIES, Carey Institute for Ecological Studies, Millbrook, New York; AMEC, AMEC, Inc. and AMEC-Foster Wheeler, Gainsville, Florida (formerly MACTEC); NRS, U.S. Forest Service Northeast Research Station, Durham, New Hampshire; RTI, RTI International, Research Triangle Park, North Carolina; UNAM, Universidad Nacional Autonoma de Mexico, Mexico City, Mexico; CEAC, Centro de Estudios Ambientales de Cienfuegos, Cienfuegos, Cuba]

\begin{tabular}{lcc}
\hline \multicolumn{1}{c}{ Participating laboratories } & $\begin{array}{c}\text { Calendar } \\
\text { years }\end{array}$ & $\begin{array}{c}\text { Number of samples } \\
\text { analyzed per lab } \\
\text { per month }\end{array}$ \\
\hline ADORC, CAL, MACTEC, MOEE, MSC, NILU, NYSDEC, SA & $2005-8$ & 8 \\
ADORC, CAL, ECST, ${ }^{1}$ MACTEC, MOEE, NILU, NYSDEC, SA & $2009-10$ & 4 \\
ACAP, ${ }^{2}$ CAL, CIES, ${ }^{3}$ ECST, MACTEC, MOEE, NILU, NYSDEC ${ }^{4}$ & 2011 & 4 \\
ACAP, AMEC, ${ }^{5}$ CAL, CIES, ECST, MOEE, NILU & 2012 & 4 \\
ACAP, AMEC, CAL, CIES, ECST, MOEE, NILU, NRS ${ }^{6}$ & $2013-14$ & 4 \\
ACAP, AMEC, CAL, CIES, ECST, MOEE, NILU, NRS, RTI ${ }^{7}$ & 2015 & 4 \\
ACAP, AMEC, CAL, CIES, ECST, MOEE, NILU, NRS, RTI, UNAM, ${ }^{8}$ CEAC $^{9}$ & 2016 & 4 \\
\hline
\end{tabular}

${ }^{1}$ The MSC laboratory changed its name to ECST because of reorganization in 2009.

${ }^{2}$ The ADORC laboratory changed its name to ACAP in 2011.

${ }^{3}$ The SA laboratory closed at the end of 2010 and was replaced by CIES in 2011.

${ }^{4}$ The NYSDEC laboratory closed at the end of 2011.

${ }^{5}$ The MACTEC laboratory changed its name to AMEC because of change in ownership in 2012.

${ }^{6}$ The NRS laboratory was added in 2013.

${ }^{7}$ The RTI laboratory was added in 2015.

${ }^{8}$ The UNAM laboratory was added in 2016.

${ }^{9}$ The CEAC laboratory was added in 2016.

\section{Sample Preparation}

A maximum of 48 samples were, and are currently (2016), distributed to each laboratory annually, which consist of 20 synthetic precipitation samples and 4 DI blank samples prepared by USGS and 24 natural wet-deposition samples blended by CAL. Natural samples and synthetic samples are shipped to the participating laboratories on alternating months. The samples are all analyzed in a single-blind mode, whereby the laboratories can identify the quality control (QC) sample type, but they do not know the target concentrations. All samples are labeled with a unique 10-digit identification (ID) assigned by USGS to ensure the participating laboratories cannot know the sample type (natural or synthetic) or the target analyte concentrations. The 10-digit ID is assigned as follows: the first 4 digits of the 10-digit sample number represent the year during which the study is conducted; the next 3 digits are the Julian date of sample mailing; and the last 3 digits are a unique ID of the sample (such as 001). For example, the 16th interlaboratory-comparison sample in the sequence, mailed to a participating laboratory on December 7, 2014, would have had the following ID: 2014341016.

There have been few changes to the protocols presented by Latysh and Wetherbee (2005) for preparation of NTN interlaboratory-comparison program samples. Stock solutions were provided by various sources prior to 2000. High Purity Standards (HPS) in Charleston, South Carolina, has supplied the stock solutions every year since 2000 except 2009. For 2009, the National Institute of Standards and Technology traceable stock solutions were obtained from R.T. Corporation in Laramie, Wyoming. Samples are shipped to participating laboratories in North America in padded envelopes. Sturdier containers are used for longer shipping distances, especially overseas. Commercially available, reusable cold packs are used to help preserve ammonium and nitrate concentrations during transport. 


\section{Data Processing}

Participating laboratories have provided analytical results to the USGS in electronic format, including Microsoft Excel and Word, ASCII, and others, via email. More recently, laboratories have entered their results directly into the BQS database by using password-protected access on the PCQA Web site (http://bqs.usgs.gov/PCQA/). Results are compiled, analyzed, posted on the World Wide Web, and published in annual reports (http://bqs.usgs.gov/). Data products on the PCQA Web site include laboratory-specific plots and interlaboratory plots. Once all laboratories have submitted their data, the most probable values (MPVs) are determined as the median concentration values for each solution. The MPVs are published in USGS reports (Wetherbee and others, 2006, 2009, 2010, 2013; Wetherbee and Martin, 2014). Results for each laboratory are compared against the MPVs, and the reported value-minus-MPV differences are presented in control charts, percent difference charts, $z$-value plots, and summary tables.

Control charts for interlaboratory-comparison program results are based on the $f$-pseudosigma statistic, a nonparametric analogue of the standard deviation defined by Hoaglin and others (1983):

$$
f \text { - } \text { pseudosigma }_{\text {overall }}=\frac{75 \text { th percentile }_{\text {overall }}-25 \text { th percentile }_{\text {overall }}}{1.349},
$$

where

75th percentile overall $_{\text {th }}$ is the 75th percentile of the reported-minus-MPV differences, and

25 th percentile overall $_{\text {over }}$ is the 25 th percentile of the reported-minus-MPV differences, for all combined laboratory results for all solutions analyzed for the year.

Warning limits are plotted on the control charts at \pm 2 times the $f$-pseudosigma ${ }_{\text {overall }}$ Control limits are plotted at \pm 3 times the $f$-pseudosigma ${ }_{\text {overall }}$. Results plotting outside the control limits are interpreted as being outside of statistical control. Positive and negative biases are evaluated by the distribution of reported-minus-MPV differences about the zero-difference line. Variability in a laboratory's results is evaluated by the consistency of the differences over time. An example control chart is shown in figure 5 . Some of the ammonium concentration differences for natural precipitation samples plot outside the control limits in figure 5, likely due to variation in ammonium stability in the split samples shipped to each of the participating laboratories. The samples are filtered, but they are not chilled or otherwise preserved.

The $f$-pseudosigma ratio ( $f$-psig ratio) is used in PCQA reports to compare an individual laboratory's variability to the overall variability:

$$
f \text {-psig ratio }=\left(\frac{f \text {-psig }}{f \text { subset }}\right)
$$

where

$f$-psig subset $_{\text {is }}$ is theseudosigma of subset for a specific laboratory, and

$f$-psig ${ }_{o} \quad$ is the overall $f$-pseudosigma of the entire dataset.

An $f$-psig ratio less than 1 indicates less variability in the specific laboratory's data relative to the overall variability. An $f$-psig ratio greater than 1 indicates higher variability in the specific laboratory's data relative to the overall variability.

The PCQA has used $z$-value plots to illustrate the degree of bias in a laboratory's reported values for a particular solution. The $z$-values are calculated for each solution as

$$
z \text {-value }=\left(\frac{\text { Medianlaboratory }- \text { Medianall laboratories }}{f \text {-psigall laboratories }}\right),
$$

where

Median
Mediaboratory
f-psig
all ll labororatories

is the median value for a solution for a participating laboratory, is the median value for a solution for all laboratories combined, and is the $f$-pseudosigma calculated from data reported by all laboratories for a particular solution. 


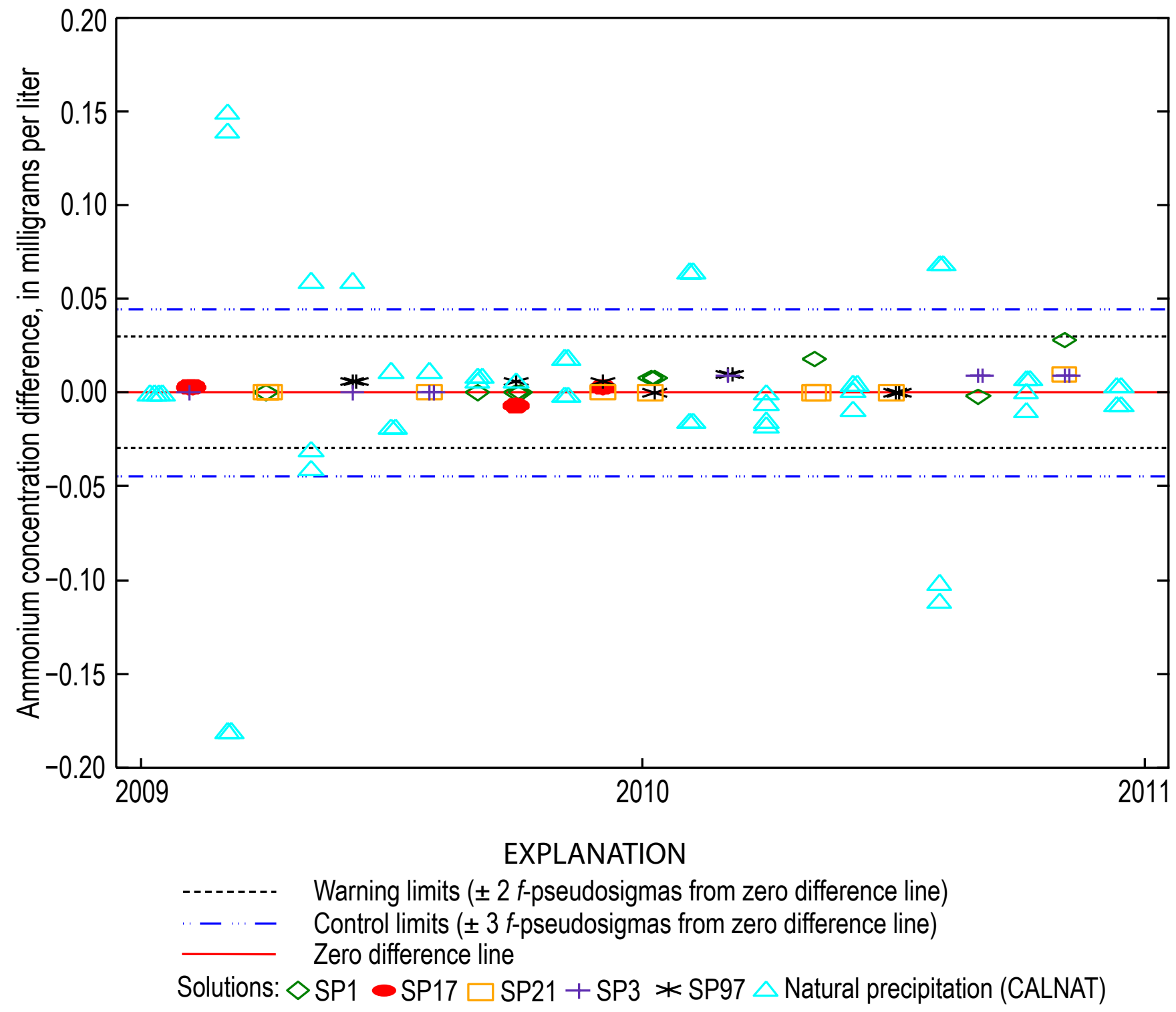

Figure 5. Example of a control chart for Central Analytical Laboratory performance for ammonium ion concentration analyses, 2009-11. (SP, synthetic precipitation)

The PCQA $z$-values are plotted as a function of concentration to indicate the relative bias between participating laboratories. An example $z$-value plot is shown in figure 6.

Natural precipitation samples are analyzed in duplicate every other month. Absolute percent differences (APDs) between the duplicate samples are calculated as follows:

$$
\text { Absolute percent difference }=\left|\frac{\left(\mathrm{C}_{\mathrm{a}}-\mathrm{C}_{\mathrm{b}}\right)}{\left(\mathrm{C}_{\mathrm{a}}+\mathrm{C}_{\mathrm{b}}\right) \times 0.5}\right| \times 100,
$$

where

$\mathrm{C}_{\mathrm{a}}$ is the original sample concentration, in milligrams per liter $(\mathrm{mg} / \mathrm{L})$ or nanograms per liter $(\mathrm{ng} / \mathrm{L})$; and $\mathrm{C}_{\mathrm{b}}$ is the replicate sample concentration, in milligrams per liter $(\mathrm{mg} / \mathrm{L})$ or nanograms per liter $(\mathrm{ng} / \mathrm{L})$. An example chart of APD values for natural precipitation sample analyses over time is shown in figure 7. Similar plots are accessible on the PCQA Web site at https://bqs.usgs.gov/PCQA/Interlaboratory_Comparison/graphOutput.php?page=start (accessed November 25, 2015). 


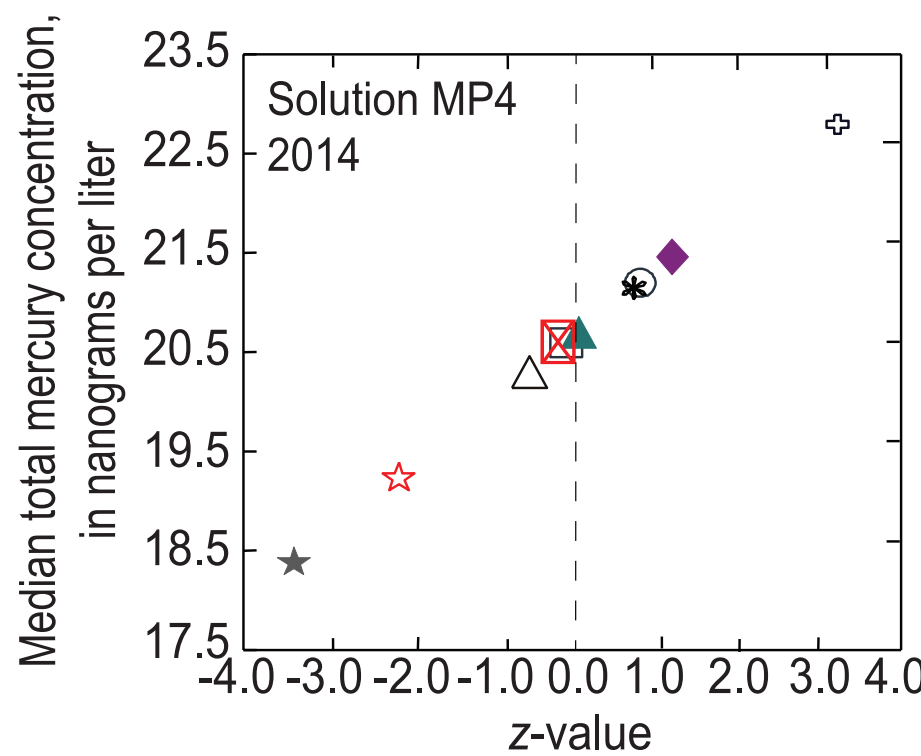

\section{EXPLANATION Laboratory}

\begin{tabular}{|c|c|c|c|}
\hline HAL & $\square 2$ & 03 & 冈4 \\
\hline$\Delta 6$ & 放 7 & $\triangle 8$ & $\Leftrightarrow 9$ \\
\hline
\end{tabular}

Figure 6. Example of a $z$-value plot for evaluation of laboratory bias in total mercury concentration analyses. (HAL, Mercury Analytical Laboratory)

\section{Mercury Deposition Network Interlaboratory Comparison}

The MDN interlaboratory-comparison program is designed to (1) quantify the bias and uncertainty of chemical analyses for concentrations reported by the HAL, (2) evaluate the analytical variability and bias of data produced by participating laboratories, and (3) enable comparison of laboratory data produced by other wet-deposition monitoring networks. The program requires participating laboratories to analyze both acidified DI solutions spiked with $\mathrm{Hg}$ and unspiked acidified DI samples by using U.S. Environmental Protection Agency Method 1631 (U.S. Environmental Protection Agency, 2002) or an equivalent atomic fluorescence spectrometry method. A diagram of the MDN interlaboratory-comparison program is provided in figure 8 . The history of laboratory participation in the MDN interlaboratory-comparison program is shown in table 5.

The interlaboratory-comparison program for MDN described by Latysh and Wetherbee (2007) has been updated as follows:

1. Participating laboratories have changed over time because of shipping constraints and the addition of international laboratories associated with the Global Mercury Observation System, an international study over 5 years that ended in 2015 (http://www.gmos.eu/, accessed November 25, 2015).

2. In January 2009 , the number of samples shipped to each laboratory was reduced to two samples per month.

3. Of the 24 samples analyzed annually by each laboratory, four samples were, and are currently, ultrapure DI water blanks with 1 percent (volume:volume) hydrochloric acid $(\mathrm{HCl})$, and 20 samples were, and are currently, 1 percent HCl-preserved DI solutions spiked with $\mathrm{Hg}$ at concentrations within the range of most MDN samples.

4. The manufacturers of $\mathrm{HCl}$ used for the samples changed from Seasstar Chemicals to J.T. Baker in April 2008, and then to $\mathrm{BDH}$ (American Chemical Society grade) in the spring of 2014. Equivalent grades of $\mathrm{HCl}$ from other manufacturers were determined to be acceptable. Changes in sources of $\mathrm{HCl}$ of similar purity were related to pricing, availability, and shipping logistics.

5. Use of Teflon bottles (500-milliliter [mL] volume, reused) for the interlaboratory-comparison samples was discontinued in 2007. Certified trace-clean borosilicate glass bottles with Teflon-lined caps of $250-\mathrm{mL}$ volume have been, and are now, used. The glass bottles are more susceptible to breaking or leaking during shipment, resulting in replacement of a small percentage of the shipped samples annually. Occasionally, the project has been unable to replace broken or leaking samples, resulting in missing data. 


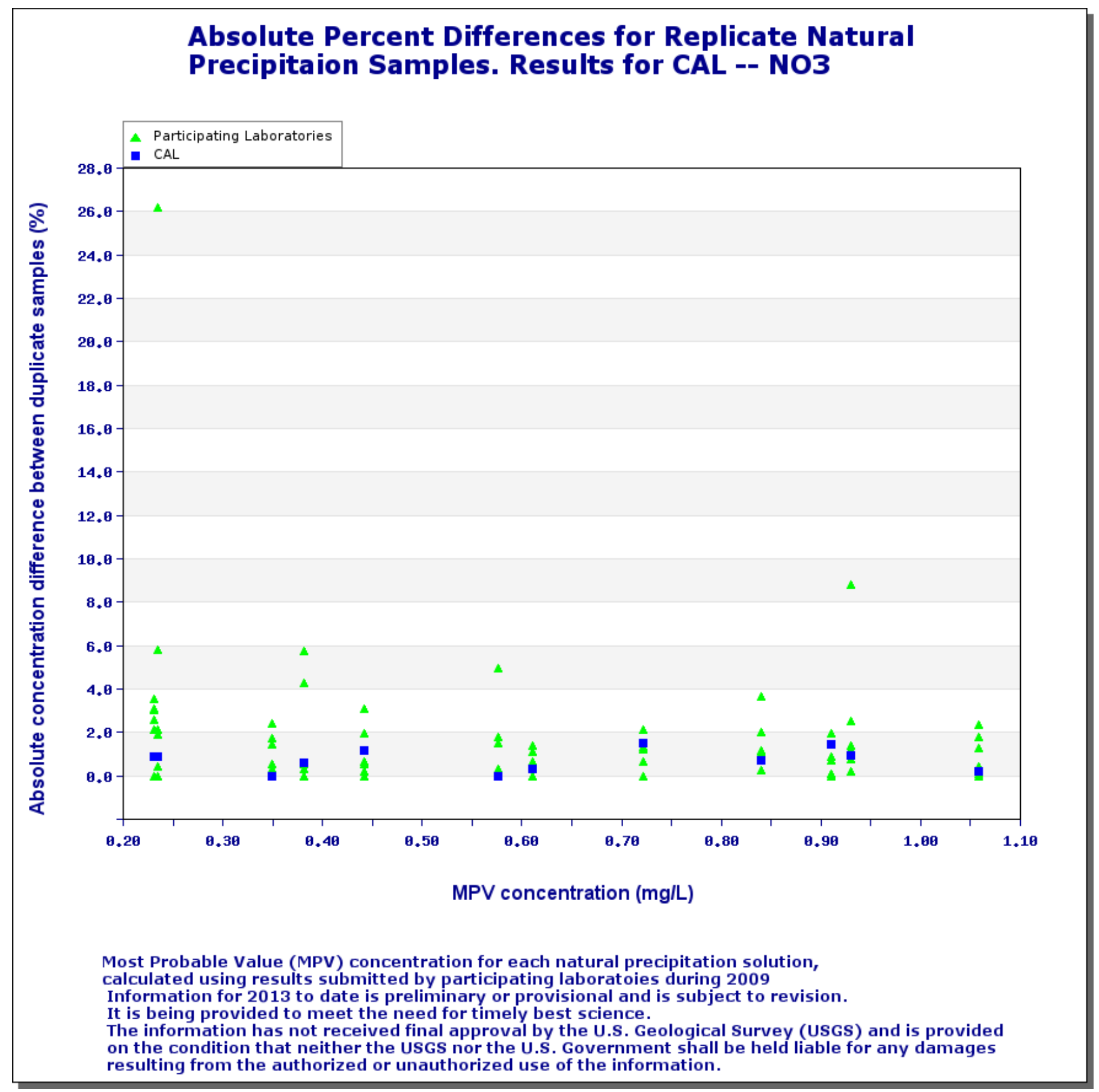

Figure 7. Example of an absolute percent difference chart for evaluation of nitrate analysis precision for the Central Analytical Laboratory (CAL) obtained from the Precipitation Chemistry Quality Assurance Project Web site (accessed at https://bqs.usgs.gov/ pcqa/, August 3, 2016). (N03, nitrate; mg/L, milligrams per liter) 
The U.S. Geological Survey (USGS) prepares blank samples and mercury $(\mathrm{Hg})$ spiked solutions: ultrapure deionized-water, National Institute of Standards and Technology standard reference materials, 1 percent hydrochloric acid.

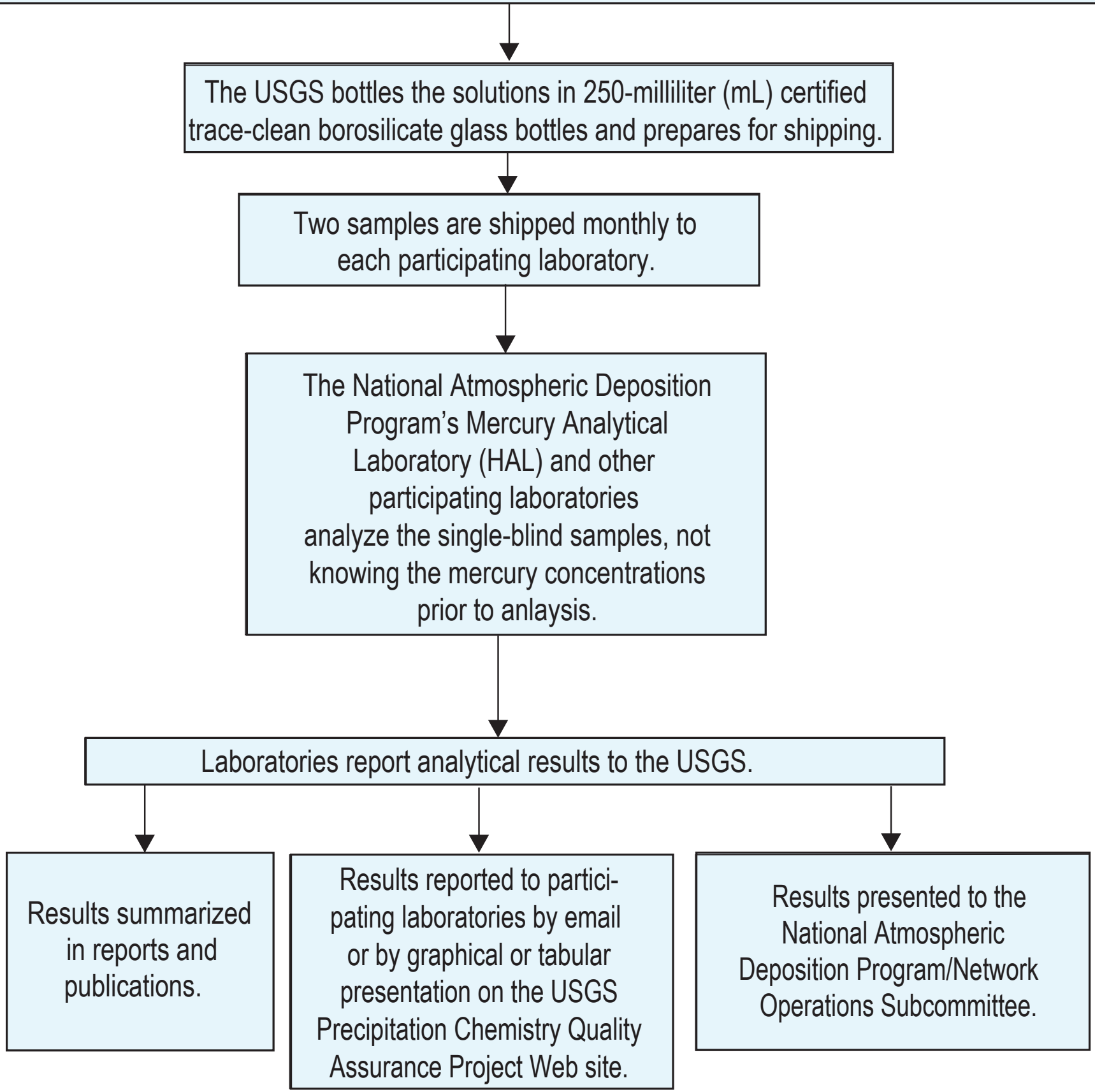

Figure 8. Diagram for the Precipitation Chemistry Quality Assurance Project interlaboratory-comparison program for the Mercury Deposition Network. 
Table 5. Historical summary of laboratory participation in the Precipitation Chemistry Quality Assurance Project interlaboratorycomparison program for the Mercury Deposition Network, 2007-16.

[ACZ, ACZ Laboratories, Steamboat Springs, Colorado; ALET, Atlantic Laboratory of Environmental Testing, Moncton, New Brunswick, Canada; FRL, Flett Reasearch, Ltd., Winnipeg, Manitoba, Canada; HAL, National Atmospheric Deposition Program Mercury Analytical Laboratory at Frontier Global Sciences and Eurofins Frontier Global Sciences, Seattle and Bothell, Washington; IVL, IVL Swedish Environmental Research Institute, Göteborg, Sweden; NLS, Northern Lake Service, Inc., Crandon, Wisconsin; NSA, North Shore Analytical, Inc., Duluth, Minnesota; VITO, Flemish Institute for Technological Research, Mol, Belgium; WML, USGS Wisconsin Mercury Research Laboratory, Middleton, Wisconsin; DASNCU, National Central University, Department of Atmospheric Sciences, Jhong-Li, Taiwan; LEEQ, Quebec Laboratory of Environmental Testing, Montreal, Quebec, Canada; CASIG, Chinese Academy of Sciences, Institute for Geochemistry, Guiyang, Guizhou, People's Republic of China; GAPMN, Umweltbundesamt/Federal Environment Agency, Langen, Germany; JSIPS, Jozef Stefan International Postgraduate School, Ljubljana, Slovenia; SGS, SGS-Belgium NV, Antwerp, Belgium]

\begin{tabular}{lc}
\hline \multicolumn{1}{c}{ Participating laboratories } & $\begin{array}{c}\text { Number of samples } \\
\text { analyzed per lab } \\
\text { per month }\end{array}$ \\
\hline ACZ, ALET, FRL, HAL, IVL, NLS, NSA, VITO, WML & 2007 \\
ACZ, ALET, FRL, HAL, IVL, NLS, NSA, VITO, WML & $2008-9$ \\
ACZ, ${ }^{1}$ DASNCU, ${ }^{2}$ FRL, HAL, IVL, LEEQ, ${ }^{3}$ NLS, ${ }^{4}$ NSA, VITO, WML & $2010-11$ \\
DASNCU, CASIG, FRL, GAPMN, HAL, ${ }^{5}$ IVL, JSIPS, LEEQ, NSA, VITO, ${ }^{6}$ WML & $2012-13$ \\
DASNCU, CASIG, FRL, GAPMN, HAL, IVL, JSIPS, LEEQ, NSA, WML & $2013-14$ \\
DASNCU, CASIG, FRL, GAPMN, HAL, IVL, JSIPS, LEEQ, NSA, SGS, ${ }^{7}$ WML & $2015-16$ \\
\hline
\end{tabular}

${ }^{1}$ The ACZ laboratory discontinued its participation at the end of 2011.

${ }^{2}$ The DASNCU laboratory began participation in June 2011.

${ }^{3}$ The ALET laboratory was replaced by the LEEQ laboratory by request of Environment Canada in 2010.

${ }^{4}$ The NLS laboratory discontinued its participation at the end of 2011.

${ }^{5}$ The HAL laboratory moved from Seattle, Wash., to Bothell, Wash., in December 2011.

${ }^{6}$ The VITO laboratory discontinued its participation at the end of 2013.

${ }^{7}$ The SGS laboratory was added in 2015 and participation was discontinued in 2016.

The MPVs for Hg concentrations in the interlaboratory-comparison program solutions have been previously published in USGS reports (Wetherbee and others, 2006, 2009, 2010, 2013; Wetherbee and Martin, 2014). The MPVs are also available in summary tables available on the PCQA Web site at https://bqs.usgs.gov/PCQA/Interlaboratory_Comparison/tableOutput. php?page $=$ start (accessed November 25, 2015).

\section{Mercury Deposition Network Blind Audit}

The blind audit program for the MDN described by Latysh and Wetherbee (2007) was discontinued in 2012. This doubleblind program was designed to disguise QC samples as real samples shipped from the field to the HAL after a dry week; however, to disguise a sample, it must be accompanied by precipitation data that indicate a nondry sampling period. Substitute precipitation records were submitted to the NADP Program Office to help disguise the blind-audit samples. Posting of the substitute data was inconsistent, and reconciliation of the data records after analysis of the blind-audit samples was complicated and resource intensive. Additionally, site operators frequently confused the blind-audit and system-blank protocols; therefore, the benefits of a double-blind program no longer outweighed the logistical challenges of its implementation. Blind Audit results are available on the PCQA Web site at https://bqs.usgs.gov/PCQA/Blind_Audit/blindAuditData.php (accessed November 25, 2015), and the results have been published in USGS reports (Wetherbee and others, 2006, 2009, 2010, 2013; Wetherbee and Martin, 2014). 


\section{References Cited}

Gordon, J.D., Latysh, N.E., and Lindholm, S.E., 2003, External quality-assurance results for the National Atmospheric Deposition Program/National Trends Network, 1997-99: U.S. Geological Survey Water Resources Investingations Report 03-4027, $75 \mathrm{p}$.

Hahn, G.J., and Meeker, W.Q., 1991, Statistical intervals-A guide for practitioners: New York, John Wiley and Sons, 392 p.

Hoaglin, D.C., Mosteller, F., and Tukey, J.W., 1983, Understanding robust and exploratory data analysis: New York, John Wiley and Sons, p. 38-41.

Latysh, N.E., and Gordon, J.D., 2004, Investigation of differences between field and laboratory pH measurements of National Atmospheric Deposition Program/National Trends Network precipitation samples: Water, Air, and Soil Pollution, v. 154 , p. 249-270.

Latysh, N.E., and Wetherbee, G.A., 2005, External quality assurance programs and procedures managed by the U.S. Geological Survey in support of the National Atmospheric Deposition Program/National Trends Network: U.S. Geological Survey OpenFile Report 2005-1024, 66 p.

Latysh, N.E., and Wetherbee, G.A., 2007, External quality assurance programs and procedures managed by the U.S. Geological Survey in support of the National Atmospheric Deposition Program/Mercury Deposition Network: U.S. Geological Survey Open-File Report 2007-1170, 33 p.

National Atmospheric Deposition Program, 1985, NADP/NTN annual data summary-Precipitation chemistry in the United States, 1982: Fort Collins, Colorado State University, Natural Resource Ecology Laboratory, 135 p.

Nilles, M.A., 2000, Atmospheric Deposition Program of the U.S. Geological Survey: U.S. Geological Survey Fact Sheet $112-00,6 \mathrm{p}$.

See, R.B., Willoughby, T.C., Brooks, M.H., and Gordon, J.D., 1990, Programs and analytical methods for the U.S. Geological Survey acid rain quality-assurance project: U.S. Geological Survey Water-Resources Investigations Report 90-4029, 17 p.

U.S. Environmental Protection Agency, 2002, Method 1631, revision E-Mercury in water by oxidation, purge and trap, and cold vapor atomic fluorescence spectrometry: U.S. Environmental Protection Agency, Office of Water report EPA-821-R-02-019, 38 p., accessed May 6, 2014, at https://www.epa.gov/sites/production/files/2015-08/documents/ method_1631e_2002.pdf.

Wetherbee, G.A., 2016, Evaluation of National Atmospheric Deposition Program measurements for colocated sites CO89 and CO98 at Rocky Mountain National Park, water years 2010-14: U.S. Geological Survey Scientific Investigations Report 2016-5051, $32 \mathrm{p}$.

Wetherbee, G.A., Latysh, N.E., and Gordon, J.D., 2004, External quality assurance results for the National Atmospheric Deposition Program/National Trends Network, 2000-01: U.S. Geological Survey Scientific Investigations Report 2004-5034, 59 p.

Wetherbee, G.A., Latysh, N.E., and Gordon, J.D., 2005, Spatial and temporal variability of the overall error of National Atmospheric Deposition Program measurements determined by the USGS collocated-sampler program, water years 1989-2001: Environmental Pollution, v. 135, p. 407-418.

Wetherbee, G.A., Latysh, N.E., and Greene, S.M., 2006, External quality assurance results for the National Atmospheric Deposition Program/National Trends Network, 2004: U.S. Geological Survey Scientific Investigations Report 2005-5067, 52 p.

Wetherbee, G.A., Latysh, N.E., Greene, S.M., and Chesney, T., 2009, U.S. Geological Survey external quality-assurance program results reported to the National Atmospheric Deposition Program/National Trends Network and Mercury Deposition Network for 2005-06: Champaign, Ill., National Atmospheric Deposition Program Quality Assurance Report 2009-01, Illinois State Water Survey Data/Case Study 2009-01, 54 p.

Wetherbee, G.A., Latysh, N.E., Greene, S.M., and Chesney, T., 2010, U.S. Geological Survey external quality-assurance program results reported to the National Atmospheric Deposition Program/National Trends Network and Mercury Deposition Network for 2007-08: Champaign, Ill., National Atmospheric Deposition Program Quality Assurance Report 2010-01, Illinois State Water Survey Miscellaneous Publication 190, 82 p. 
Wetherbee, G.A., and Martin, R.A., 2014, U.S. Geological Survey external quality-assurance program results reported for the National Atmospheric Deposition Program/National Trends Network and Mercury Deposition Network for 2011-2012: Illinois State Water Survey Miscellaneous Publications Report 14-01, QA Report 14-01, 49 p.

Wetherbee, G.A., Martin, R.A., Rhodes, M.F., and Chesney, T.A., 2013, U.S. Geological Survey external quality-assurance program results reported for the National Atmospheric Deposition Program/National Trends Network and Mercury Deposition Network for 2009-2010: U.S. Geological Survey Scientific Investigations Report 2013-5147, 53 p. 

